\title{
O CONSUMO NO PERIÓDICO MEN'S HEALTH
}

THE CONSUMPTION IN MEN'S HEALTH MAGAZINE

Douglas Geraldo Brandão Ribeiro ${ }^{1}$

\section{Resumo}

Trata-se de um estudo a respeito da imagem ideal da masculinidade veiculada no periódico Men's Health e das estratégias de marketing utilizadas pelos anunciantes para alcançar seus leitores. Para tanto, tem-se como objeto de estudo as publicações da revista masculina de circulação nacional Men's Health dos meses de junho e dezembro de 2009. Nesse sentido, este artigo discute, em linhas gerais, questões como identidade, masculinidade, mídia, desejos, necessidades, representações. Além das perspectivas abordadas pelos Estudos Culturais, esta pesquisa tem por fundamentação os pressupostos de Lipovetsky (1989), Hall (1999), Vestergaard; Schroder (2004), Canclini (2008), Allérès (2006) e Cidreira (2005).

Palavras-chave: Masculinidade; Identidade; Estudos Culturais; Mídia.

\section{Abstract}

It deals with the image of an ideal masculinity spread on the magazine Men's Health and the maketing strategies used by the advertisers to convince the audience. Therefore, the objects of study are the June and December issue of national masculine magazine Men's Health. So there, this article, by and large, deals with identity, masculinity, media, fulfills, needs, representations. Besides the perspectives broached by the Cultural Studies, this research is based upon the tenets of Lipovetsky (1989), Vestergaard; Schroder (2004), Canclini (2008), Allérès (2006) and Cidreira (2005).

Keywords: Masculinity; Identity; Cultural Studies; Media.

${ }^{1}$ Discente do curso de Línguas Estrangeiras Aplicadas às Negociações Internacionais - LEA da Universidade Estadual de Santa Cruz (UESC), orientando da professora Msc. Sylvia Maria Campos Teixeira, e-mail: doug_branco@hotmail.com. 


\section{Introdução}

O consumo participa diretamente da metamorfose social como instrumento indispensável para a alocação dos novos paradigmas modernos que elevam o sujeito ao status de cidadão (CLANCLINI, 2008). É através das práticas de consumo que o indivíduo se autoafirma como pertencente a um determinado grupo social e adquire uma personalidade prófuga na medida em que o exercício de tais práticas não é estático, mas varia conforme o seu grau de instrução e o seu poder aquisitivo. Segundo Lipovetsky (1989), a sociedade de consumo apresenta traços particulares que lhe conferem uma identidade caracterizada pela elevação do nível de vida, pela abundância das mercadorias e dos serviços, pelo culto dos objetos e dos lazeres e pela moral hedonista e materialista. Aliados aos referidos fatores, que influenciam diretamente as práticas de consumo, estão o gosto pela novidade e a fugacidade da moda como os principais responsáveis pela curta permanência dos produtos nas práticas sociais cotidianas (CIDREIRA, 2005).

Através da análise dos produtos anunciados e das estratégias de comunicação da revista masculina Men's Health dos meses de junho e dezembro de 2009, busca-se compreender as expectativas dos anunciantes quanto às necessidades dos homens, o conhecimento das estratégias mercadológicas utilizadas para atrair o público-alvo e como os ideais de masculinidade são veiculados na referida revista. Para tanto, busca-se na literatura pesquisada de autores, como Lipovetsky (1989), Hall (1999), Vestergaard, Schroder (2004), Canclini (2005), Allérès (2006) e Cidreira (2005), as teorias que explicam os mecanismos psicossociais responsáveis pela super valorização dos costumes que caracterizam o convívio social e, portanto engendram o processo conhecido na literatura dos referidos teóricos como a teatralização da vida cotidiana e a necessidade de auto-afirmação através da escolha dos produtos consumidos (STREHLAU, 2008).

Este trabalho está dividido em três partes: a primeira aborda, por meio de teorias dos referidos autores e da análise das formas de consumo, a necessidade do indivíduo de afiliar-se a um grupo social. Na segunda, procura-se estabelecer uma relação entre as expectativas dos anunciantes da revista Men's Health e as práticas de consumo dos seus leitores. E na terceira, mostra-se os ideais de masculinidade vigentes nas práticas de publicidade das páginas da Men's Health. 


\section{A justificativa do consumo}

"O que é consumido é a sociedade de consumo, como valor cultural global".

Jean Baudrillard

O consumo representa o limiar tênue que divide as várias categorias sociais e, portanto, age como instrumento diferenciador do sujeito social que deseja distinguir-se do meio profissional, cultural e social em que está inserido. Também serve para pensar os mecanismos de aquisição cultural de que dispõe a sociedade, neste caso, é levado em consideração o consumo dos meios de comunicação.

A consequiência desse processo de aquisição midiática é a formação de uma identidade estruturada em torno de comunidades de consumidores, como os jovens em torno da música pop e os homossexuais em torno da cultura gay. Esse sentimento de pertença é descrito por Canclini (2008), como sendo:

(...) organizado cada vez menos por lealdades locais ou nacionais e mais pela participação em comunidades transnacionais ou desterritorializadas de consumidores (os jovens em torno do rock, os telespectadores que acompanham os programas da CNN, MTV e outras redes transmitidas por satélite) (CANCLINI, 2008, p.40).

Nesse sentido, o consumo, embora seja um ato de expressão individual, também pode representar a expressão dos ideais coletivos vigentes. Para tanto, são considerados os aspectos social, cultural e simbólico, largamente difundidos pela mídia massificada (STREHLAU, 2008).

Através da prática de consumo, que pode até mesmo representar uma experiência única, o sujeito revela a sua ética para o meio social em que está inserido. É através dos relatos cotidianos de compras que o indivíduo demonstra bom gosto, conhecimento sobre moda, tendências, cultura, refinamento e viagens. Dessa forma, segundo Hall (1999), o indivíduo é formado subjetivamente através de sua participação em relações sociais mais amplas, neste caso, a interação do sujeito com o meio social em que vive através dos relatos de aquisição de bens e, inversamente, o modo como os processos e estruturas são sustentados pelos papéis que os indivíduos neles desempenham como a diferenciação social advinda da categoria de consumo. Ainda de acordo com o referido autor, 
Essa “internacionalização' do exterior no sujeito, e essa “externalização” do interior, através da ação no mundo social, constituem a descrição sociológica primária do sujeito moderno e estão compreendidas na teoria da socialização (HALL, 1999, p.31).

Os consumidores estão ligados por pactos móveis de leitura dos bens e das mensagens (CANCLINI, 2008). Nesse sentido, o consumo é o meio pelo qual o cidadão se afilia a um estrato social bem delimitado pelos códigos sociais que engendra. Os critérios de afiliação são, dessa forma, estabelecidos com base na decodificação dos signos inerentes à veiculação de informações, de moda e do conhecimento. Esse novo paradigma estabelecido tem como conseqüência o nascimento de um sentimento de pertença nacional alicerçado menos no território e na política que nas comunidades de consumidores.

\title{
A busca pela identidade através do consumo
}

\begin{abstract}
"Dê-lhe todas as satisfações econômicas, de modo que já nada tenha a fazer senão dormir, devorar brioches e se dar ao trabalho de prolongar a história universal; cumule-o de todos os bens da terra, e mergulhe-o na felicidade até a raiz dos cabelos: pequenas bolhas arrebentarão na superfície dessa felicidade, como por sobre a da água".
\end{abstract}

Dostoievski (apud ALLÉRÈ)

O consumo pode ser classificado segundo as práticas de consumo de três conjuntos de bens. Segundo Featherstone (1995), esses conjuntos correspondem primeiro a um conjunto de artigos de consumo geral, correspondente ao setor primário de produção (comida, por exemplo); segundo, a um conjunto tecnológico, correspondente ao setor secundário de produção (percurso e equipamento capital do consumidor) e, finalmente, a um conjunto de informação, correspondente à produção terciária (bens de informação, educação, artes, atividades culturais e de lazer).

Ainda de acordo com Featherstone (1995), as camadas mais baixas da sociedade limitam-se à aquisição de bens de consumo geral. Para a mudança dos paradigmas de consumo, isto é, para a ascensão das práticas de consumo é necessário haver disposição de capital econômico e capital cultural para a decodificação dos símbolos e signos inerentes aos bens não pertencentes ao consumo geral. 
O tempo empreendido nas práticas de consumo e na aquisição de competências para gerir informações, bens e serviços constitui um critério útil de classe social (FEATHERSTONE, 1995). Através de uma conversa com os membros do seu entorno social, o sujeito pode revelar o conhecimento, adquirido ao longo de leituras e viagens, acerca de obras de arte, produções musicais, filmes independentes, óperas, livros de autores considerados complexos e ainda roupas de griffes exclusivas. Dessa maneira, o conhecimento dos novos bens, seu valor social e cultural, e a forma de como apropriar-se adequadamente deles se torna indispensável para a afiliação e, portanto, a descoberta de uma nova identidade, em determinados grupos exclusivos.

Alguns autores destacam a importância do estilo, das grandes marcas e dos produtos da moda, sujeitos a constantes mudanças, imitação e cópia, para a classificação do outro. Os bens adquiridos na experiência única e exclusiva de compra são os parâmetros medidores do status e do prestígio.

A incessante busca por status e prestígio compõe o processo de teatralização dos costumes, isto é, a composição de personalidades sociais através dos produtos consumidos pelos atores sociais. As atitudes do sujeito moderno, estabelecidas através de ditames tirânicos veiculados pela publicidade, engendram o processo de estetização da vida. O maior expoente desse processo é a modelagem corporal. A esse respeito, Cidreira (2005) escreve:

Esta imagem típica é veiculada pelas mídias, via a publicidade, a moda e seus desfiles de manequins de corpos perfeitos. É indispensável portar tal vestimenta, tal maquiagem, tal penteado, e utilizar tal creme (...) etc., para aproximar-se dos modelos midiáticos (CIDREIRA, 2005, p. 15).

O periódico tomado como objeto de estudo deste trabalho, a Men's Health, veicula através dos seus anúncios um conteúdo simbólico carregado de apologia à sensualidade do corpo masculino modificado através de dietas e exercícios físicos severos. As matérias publicadas, geralmente, tratam sobre como alcançar o corpo perfeito e sobre como tornar-se atraente. A publicação do mês de junho traz como matéria principal "A comida para ficar sarado, músculos em tempo recorde" e as matérias secundárias tratam sobre como "entrar em forma sem sair de casa". Os ditames tirânicos são observados nessas matérias através da utilização de verbos no imperativo que denotam a imposição de práticas por parte da revista entendidas pelos leitores como a solução dos seus conflitos estéticos e existenciais. $\mathrm{Na}$ matéria secundária intitulada "Monte seus músculos" percebe-se a presença do referido tempo 


\section{DIVERS@!}

verbal nos passos a serem seguidos para se alcançar o corpo ideal, como, "coma mais gorduras", "não exagere no treino", "corte a proteína", "beba água”, "tempere com sal” etc.

A publicidade veiculada na referida revista do mês de junho, revela a expectativa do anunciante quanto ao estilo dos seus leitores. Em "Seja cool na crise", nota-se nas "10 regras para um novo estilo" a imposição de normas de vestuário ao público masculino leitor que o conduzirá ao status de "cavalheiro moderno", conforme promessa da revista. Por meio de recursos diversos como, a utilização de pesquisas da Universidade da Flórida (EUA), a Men's Health apela para a aparência de bem-sucedido e poderoso que o leitor deve ter na hora de atrair o sexo feminino para os seus domínios cavalheirescos.

A edição de dezembro traz um especial de nutrição. A matéria da capa é intitulada "Coma bem e fique enxuto, o cardápio ideal do verão". Em "Turbinada final, chegou a hora de impressionar as mulheres na areia. Não teve tempo de turbinar o corpo? Relaxe: a gente tem o plano para seus músculos saltarem em tempo recorde" a revista faz um apelo à importância de um corpo bem trabalhado pelos exercícios físicos e, portanto, modificado no momento da conquista do ser desejado. Ao longo da matéria, o autor delega aos leitores a responsabilidade de impressionar as mulheres com uma "barriga de tanquinho" ou decepcioná-las com uma "pança".

\section{As práticas de consumo na Men's Health}

O corpo, a pele, na sua nudez apenas, não tem existência possível. O organismo não é aceitável a menos que seja transformado, coberto de signos. O corpo só fala quando é vestido de artifícios.

Borel (1999)

A seção Estilo, da edição de junho da Men's Health, traz uma matéria sobre os cuidados pessoais intitulada "Vaidade tem hora" que promete um "look impecável" e revela a importância da apresentação pessoal para os seus leitores. A gama variada de marcas composta por Racco, Issey Miyake, Nivea, O Boticário Men, Natura, Rexona Men, Christian Lacroix e outras, presentes nos anúncios da referida revista, comprovam a disposição do público masculino para o cuidado excessivo com a aparência, através de produtos como protetor solar, creme hidratante, pós-barba, sabonete facial, gel de cabelo, anti-rugas, 
esfoliante para o rosto, anti-sinais e tônico adstringente. A partir de então, nota-se maior participação do homem no mercado da estética, antes restrito ao universo feminino. Os meios de comunicação, neste caso as revistas, são os responsáveis pela emissão de conteúdos que encorajam o rompimento de barreiras simbólicas entre os homens e as mulheres.

$\mathrm{Na}$ moda, o vestuário representou o apogeu da quebra dos paradigmas que delimitavam ordenadamente os gêneros masculino e feminino. Por um lado as calças foram "retiradas" do guarda-roupa masculino e passaram a representar a reivindicação feminina por uma realocação na estrutura social ultrapassada e majoritariamente patriarcal. Em contrapartida, no século XIX tem lugar o surgimento de um novo personagem social, categoricamente intitulado dândi pela literatura, que se valia de peças pertencentes ao guardaroupa feminino e possuía meios suficientes para se vestir de forma excêntrica. Para Crane, o dândi "adota cores normalmente associadas a mulheres, como branco e pastel, em especial rosa e azul" (CRANE, 2006, p. 382).

Quando emitem significados que são, não raro, decodificados pelos participantes de uma mesma categoria social, os cidadãos tornam o consumo o fator indispensável ao processo de caracterização dos papéis sociais a serem desempenhados pelo sujeito moderno desejoso de teatralizar os seus costumes na tentativa de afiliar-se a uma categoria social distinta. Dessa forma, destaca-se a importância do símbolo e do signo para o ritual do consumo. Segundo Allérès (2006), a função essencial dos signos e códigos modernos de referência social dos objetos é "a constituição, o reconhecimento e o respeito de uma hierarquia de classes sociais, no plano de seu consumo no meio de uma sociedade e pela sua modificação ao longo da evolução de sua historia” (ALLÉRÈS, 2006, p. 51).

Nas páginas da Men's Health aqui analisadas, o culto à novidade é percebido através da categorização do homem que é recompensado com o título de "cavalheiro moderno" por suas conquistas amorosas e pela adoção de um estilo. Essa imposição cultural é característica das sociedades modernas e revela um resgate aos antigos ideais cavalheirescos de preciosidade galante do homem fortemente inclinado as artes, a dança, a moda e a literatura. Lentamente, o homem guerreiro e provedor cede lugar ao verdadeiro cavalheiro que sabe cortejar uma mulher (CIDREIRA, 2005).

A passagem do homem conquistador para o homem ligado às artes - romancistas, poetas e pintores - se dá de forma desafiadora para o sexo masculino, pois, segundo Sant'Anna (1997), ele tem de se reconhecer como masculino vivenciando coisas do universo feminino. Ainda para a referida autora, 
[...] é impossível se pensar em um modelo de masculino, pois, esta síntese não dá para ser resgatada, já que o sentido totalizador do mundo é algo superado, é algo não vigente e condizente com a vivência das pessoas. $\mathrm{O}$ mundo hoje vive (e reinvidica) uma existência do plural, do indivíduo múltiplo vagando e manipulando uma teia de identidades (SANT'ANNA, 1997, p. 91).

A esse respeito, Hall (1999) escreve que:

[...] conceptualizado como não tendo uma identidade fixa, essencial ou permanente [...] A identidade plenamente unificada, completa, segura e coerente é uma fantasia. Ao invés disso, à medida que os sistemas de significação e representação cultural se multiplicam, somos confrontados por uma multiplicidade desconcertante e cambiante de identidade possíveis com cada uma das quais poderíamos nos identificar - ao menos temporariamente (HALL 1999, p. 13).

Através dos anúncios da Men's Health é possível perceber as expectativas dos anunciantes para os seus leitores. A edição de dezembro está de acordo com os Estudos Culturais de Hall que anuncia um individuo formado por uma "multiplicidade" de identidades, ao invés de uma só, como se costumava imaginar o homem. Nas páginas dos anunciantes, encontram-se produtos de alta tecnologia, como a tecnologia da TV KDL - 52 XBR9 e a câmera ST1000 anunciadas na seção Conectividade, pacotes de festas, como o carnaval de Salvador, anunciados pelo Camarote Harem Carnaval 2010 e ainda mapeamentos bioquímicos apresentados pela Ethosclin como alternativa para emagrecimento. Fica claro que a publicidade veiculada nas páginas da revista tratada neste trabalho é dirigida aos homens que viajam, que buscam alívio do stress cotidiano causado pela rotina do trabalho e que estão em sintonia com o desenvolvimento de novas tecnologias. Esses são alguns dos traços característicos da mentalidade pós-moderna incutidos nas mensagens transmitidas aos leitores da Men's Health.

No anúncio dos aparelhos Galaxy/Galaxy Life, Omnia Pro, Omnia II e Jét da Sansung, percebe-se a alocação estratégica do nome da marca no canto superior esquerdo da página e a logomarca e o endereço eletrônico no canto inferior direito. A esse respeito, Vestergaard e Schroder (2004) escrevem que a alocação dos itens mais importantes transmitidos pelos anunciantes em uma tela ou página de uma revista, é estrategicamente escolhida de acordo com o campo de visão dos receptores, neste caso, da esquerda para a direita, do canto superior 
para o canto inferior. $\mathrm{O}$ que os autores esclarecem em suas pesquisas é que este é o campo de visão privilegiado pelos receptores de mensagens escritas, ou televisionadas, quer dizer, existe uma tendência inconsciente à visualização diagonal das páginas de anúncios de revistas, outdoors ou telas de cinema ou televisão.

\section{Consideraçãoes Finais}

Os paradigmas modernos do consumo sofreram alterações significativas que redirecionaram a política de padronização do gosto dos consumidores e os tornaram mais independentes no que diz respeito a suas escolhas. De acordo com Cidreira (2005, p. 77), "se torna visível um novo perfil de consumidor seletivo, exigente e em, ultima instancia, independente para efetivar suas escolhas, fazendo mesmo combinações inesperadas, surpreendentes".

A busca pelos padrões estabelecidos pela mídia revela a lacuna existente na identidade do homem moderno, receoso de quem é e desejoso de alcançar o ideal pré-estabelecido pelas revistas e agências de publicidade. De acordo com as análises da seção "carta aos leitores" da revista aqui tratada, percebe-se a fragilidade do público da referida revista quanto à imposição dos anunciantes na divulgação de marcas, bebidas, comidas, calçados e perfumes. Parece que o homem de negócios, o mecânico, o professor, o arquiteto, o dentista, o empresário, entre outros, cederam aos encantos do cavaleiro moderno, retratado nos anúncios da revista como o perfeito sedutor, dotado de sensibilidade e beleza, que assume seu posto de senhor absoluto da pós- modernidade e toma o lugar do macho provedor.

O ressurgimento do dândi moderno, capaz de transcender-se por meio do consumo de itens que preenchem o seu vazio identitário contemporâneo, engendra uma série de mecanismos sociais de consumo desenfreado que modificam as paisagens econômica e natural. Esse é o destino das sociedades modernas condenadas à teatralização das suas práticas cotidianas.

\section{Referências}

ALLÉRÈS, D. Luxo...: estratégias de marketing. Rio de Janeiro: FGV, 2006. 


\section{DIVERS@!}

CANCLINI, N. G. Consumidores e cidadãos: conflitos multiculturais da globalização. 7. ed. Rio de Janeiro: UFRJ, 2008.

CIDREIRA, R. P. Os sentidos da moda: vestuário, comunicação e cultura. 2. ed. São Paulo: Annablume, 2005.

CRANE, D. A moda e seu papel social: classe, gênero e identidade das roupas. São Paulo: Senac, 2006.

FEATHERSTONE, M. Cultura de consumo e pós-modernismo. São Paulo: Studio Nobel, 1995.

HALL, S. A identidade cultural na pós-modernidade. 3.ed. Rio de Janeiro: DP\&A, 1999.

LIPOVETSKY, G. O império do efêmero: a moda e seu destino nas sociedades modernas. São Paulo: Companhia das Letras, 1989.

SANT'ANNA, P. O rito da moda: um estudo sobre as revistas especializadas. Campinas: monografia (IFCH/UNICAMP), 1997.

VESTERGAARD, T.; SCHRODER, K. A linguagem da propaganda. 4. ed. Tradução João Alves dos Santos. São Paulo: Martins Fontes, 2004.

STREHLAU, S. Marketing do luxo. São Paulo: Cengage Learning, 2008. 